\title{
A ESCASSEZ DA PRESENÇA FEMININA NOS DEPARTAMENTOS DE CRIAÇÃO DAS AGÊNCIAS DE PUBLICIDADE BRASILEIRAS E SUAS CONSEQUÊNCIAS PARA A REPRESENTAÇÃO DE GÊNERO
}

\section{Daniella Zarro Teixeira Silva Pinto' \\ Flavia dos Santos Cardoso ${ }^{2}$}

\begin{abstract}
Resumo: Este artigo irá observar como a escassez da presença feminina nos departamentos de criação das agências de publicidade brasileiras se relaciona com a concepção de peças e campanhas publicitárias machistas, influenciando diretamente na disseminação de valores que reforçam a desigualdade de gênero. Por meio de pesquisa bibliográfica, documental e estudo de caso, utilizando como fonte estatísticas de organizações como 65/10, Think Eva e Instituto Patrícia Galvão, além de notícias e depoimentos veiculados em portais como Carta Capital, Folha de São Paulo, AdNews e Meio \& Mensagem, discute-se as razões da dificuldade em quebrar esses padrões, enraizados na sociedade, na cultura e refletidos no ambiente de trabalho. Compreende-se que a publicidade tem poder e responsabilidade sobre a formação da opinião comum e pode se utilizar disso para reverter uma estrutura discriminatória. Porém, e antes disso, a publicidade precisa questionar sua própria estrutura, que não oferece plena abertura para a igualdade e representação.
\end{abstract}

Palavras-chave: Mulher; Publicidade; Agência; Machismo.

\footnotetext{
1 Universidade do Vale do Paraíba, Brasil. E-mail: daniellazarro-@hotmail.com.

2 Universidade do Vale do Paraíba, Brasil. E-mail: flavia.univap@gmail.com.
} 